\title{
OTA squares circle of dissent
}

Washington

THE Office of Technology Assessment (OTA) has weighed in to the debate over the use of animals in research with a report that even critics regard as comprehensive, and which will have to be reckoned with in any future debates on the subject.

More than two years in the making, at a cost of $\$ 425,000$, the report (Alternatives to Animal Use in Research, Testing and Education) looks into alternatives to the use of animals, not just in research, but in education and testing as well, judging

\section{Guidelines off \\ Washington \\ THE new guidelines adopted by the Nation-} al Science Teachers Association (NSTA) for animal use in US elementary and secondary schools will not be endorsed by the National Academy of Sciences.

While the Office of Technology Assessment (OTA) report indicates that the "overwhelming majority" of animals used in research and testing are governed by some sort of institutional review process, the same cannot be said for the use of animals in education, especially at the elementary and secondary school levels.

What guidance there is comes primarily from guidelines established by NSTA and the National Association of Biology Teachers (NABT).

In 1981, NSTA submitted its guidelines to the National Academy of Sciences, and they were eventually endorsed by the National Research Council. The guidelines prohibit "experimental procedures on mammals, birds, reptiles, amphibians or fish that cause the animal pain". The 1981 guidelines also state that "students shall not perform surgery".

But not all members of NSTA and NABT were content with these restrictions. Many felt that they would hamper the education of outstanding students. Moreover, the guidelines were more restrictive than those accepted by the International Science and Engineering Fair, which sets standards for many school science fairs.

So in 1985, NSTA rewrote the guidelines. The language was altered to read that no experiment causing "unnecessary pain" should be performed, and surgery was permitted, so long as it was supervised.

In December, NSTA resubmitted their guidelines to the academy, hoping for endorsement. But the academy declined, although it has yet to issue a public statement on the matter. One possibility is that the academy will issue its own guidelines later this year, and these are likely to conform more closely to the 1981 NSTA guidelines.

Joseph Palca them by the extent to which they replace, reduce and refine present techniques.

While acknowledging that "some biological research requires - and in the foreseeable future will continue to require - the use of live animals", the report notes that the alternatives to tests such as the $\mathrm{LD}_{50}$ test that are now more widely adopted in industry, and looks for potential parallels elsewhere in testing and research. To reduce the use of animals in science, the role of computers can be expanded beyond that of a tool for modelling animal behaviour. Using computers to improve information exchange about data already collected can eliminate redundancies in research. But the report acknowledges that the United States lags behind European countries and Japan in the protection of laboratory animals.

Difficulty in estimating the numbers of animals bedevils attempts to evaluate current usage. The best data come from the Animal and Plant Health Inspection Service (APHIS) of the US Department of Agriculture, which collects records on the use of dogs, cats, hamsters, rabbits, guinea pigs and non-human primates. This group of animals represents only about 10 per cent of animal use; reporting on rats, mice and birds is not required. Extrapolating from these numbers, OTA estimates that between 17 and 22 million animals were used during 1983 in research and testing.

Even before the report was officially released, some groups were rejecting it. The People for Ethical Treatment of Animals calls the report biased, saying that it does not reflect the views of the animal rights movement. Connie Kagan of the Animal Political Action Committee calls it "disappointing", and doubts if it will have much impact on Congress.

But most observers agree that the report is as comprehensive as could be reasonably expected, and Barbara Orlans of the Scientists' Center for Animal Welfare, believes it will be "recognized as a bible".

Sensitivity about the use of animals in science has been growing recently in the United States. The Animal Welfare Act was amended last year, strengthening its provisions, and the Health Research Extension Act of 1985 puts the force of law behind some parts of the current Public Health Service guidelines on animal use. These changes in federal law have shifted much of the responsibility for oversight of animal use onto institutional review committees, and OTA estimates that "the overwhelming majority of experimentalanimal users in the United States" now come under the oversight of a "structured, local review committee".
Perhaps the single greatest accomplishment of the report is that it seems to have generated surprisingly little acrimony. According to Arthur Caplan, chairman of the OTA advisory panel, the report transcends "the name calling, finger pointing and hair pulling that normally accompanies the discussion of animal use in science".

Joseph Palca

\section{Preaching to converts}

\section{Washington}

Growing awareness may have inspired the report of the Office of Technology Assessment (OTA) on alternatives to animal use, but in the commercial field, business savvy may provide its own reasons for abandoning animal resources. So Charles River Biotechnical Services (CRBS) joined the industry-wide shift from in vivo to in vitro monoclonal antibody production with last month's purchase of the Opticell branch of KC Biologicals. Executive vicepresident Melvin Balk says the acquisition will expand the Massachusetts company's bioprocessing services to include vaccines and recombinant proteins, while Opticell's culture system will gradually usurp the mouse as CRBS's antibody factory.

Balk also served on the advisory panel for OTA's project, as much, he says, to scout for alternatives that make "economic sense" as to further OTA's evaluation. In the case of cell culture methods for monoclonal antibody production, economic sense and ethical sensitivities coincide. Balk says the techniques avoid costly problems associated with, for example, varability and contamination of mouse monoclonals. But the success of these methods is still contingent on improvements in product yield and the stability of large-scale markets. Although in vitro products such as human chorionic gonadotropin are aimed at high-demand diagnostic or therapeutic markets, most in vitro methods cannot yet equal the milligram per millilitre harvest that mice supply.

Echoing OTA's conclusion, Balk insists that mice will always be necessary for monoclonal production because some hybridomas simply will not thrive elsewhere. Other industry experts paint a more optimistic picture for the future of cell culture. Allan Jarvis at Damon Biotech anticipates a time when in vivo production may be superfluous and outdated; Damon has survived five years without it. At Becton-Dickson in California, the mood is more cautious. Before launching an in vitro programme, the company's attempts to evaluate different culture systems have been frustrated because these systems are still in their largely untried infancy. The venture will probably be risky and, as one manager remarks, a half-million-dollar mistake is not a welcome alternative to animal use.

Karen Wright 